\title{
Aspects of Particle-Dispersant Interaction - Mode of Attachment of Dispersants to Particles
}

\author{
Claus Pade* and S. Chatterji
}

Danish Technological Institute, Gregersensvej, DK-2630, Denmark

\begin{abstract}
Dispersing chemicals are often used to improve the properties of concrete. In the cement field these chemicals are known as superplasticizers. Basically, the superplasticizers can be divided in to two classes: mainly negatively charged ionic and mainly non-ionic. The backbones of both types of superplasticizers are hydrophobic aliphatic and/or aromatic chains. To function as superplasticizers, these chemicals have to attach themselves to the solid particles of cement pastes. Ionic superplasticizers are generally assumed to attach themselves to positively charged solid particles by electrostatic bonds. The mode of attachment of non-ionic superplasticizers is not well specified.

In this paper, the modes of attachments of both the types of superplasticizers have been reexamined. It is known that silica powder is positively charged below $\mathrm{pH} 3$ and negatively charged above $\mathrm{pH}$ 9. Advantage has been taken of this charge reversal of silica powder to study the modes of attachment of both types of superplasticizers. It is observed that negatively charged $\beta$-SNFC functions equally well both with pastes of positively and negatively charged silica particles.This means that $\beta$-SNFC can attach itself to silica particles irrespective of sign of charge on the particles.

Function of a non-ionic superplasticizer is found to be very sensitive to the number density of the solid particles. At high number density this type of dispersant can act as flocculants irrespective of the sign of charge on silica particles. At low number density of solid, this type performs in alkaline medium.

From the above results it has been postulated that all types of superplasticizers attach themselves by depositing their hydrophobic part on to the solid particles. The effects of this type of attachment have been discussed.
\end{abstract}

\section{INTRODUCTION}

Superplasiticising, i.e. dispersing chemicals are often used to improve the properties of concrete e.g. either to improve its flow property or to improve its strength and /or durability by reducing its water demand. This has resulted in a large volume of researches on the chemistry and physics of these chemicals. Different aspects of this vast literature have been reviewed by Flatt [1]. Chemically superplasticizers may be classed as polymers with hydrophilic side radicals. These hydrophilic radicals could be ionic like sulphonate, carboxylate or hydroxyl groups or long chain ethylene oxides. The backbones of superplasticizers are either aliphatic and/or aromatic compounds e.g. poly-naphthalene formaldehyde condensate. These polymeric backbones are hydrophobic. In each case the ratio of hydrophilic/ hydrophobic components is such that the polymer becomes water soluble. This is an aspect of empirical HLB (hydrophilic-lipophilic balance) scheme [2]. Many of the earlier commercial superplasticizers were linear polymers with many ionic side groups e.g. poly$\beta$-naphthalene sulphonate formaldehyde condensate $(\beta$ SNFC), poly-melamine sulphonate formaldehyde condensate (SMFC). Recent superplasticizers tend to be of 2 or 3 dimensional configurations and generally contain only few ionic radicals per polymer. Commercial products are generally mixtures of different degree of polymerisation and may

*Address correspondence to this author at the Danish Technological Institute, Gregersensvej, DK-2630, Denmark, Tel: +45 72202183; Fax +45 72202372; E-mail: Claus.Pade@ @eknologisk.dk contain different hydrophilic and hydrophobic radicals in a single polymer molecule. For superplasticizers to work they must attach to the surfaces of the cement particles and/or cement hydration products. It is a common experience that once these chemicals attach themselves to cement grains they are extremely difficult to remove [3]. This means that the cement-superplasticizer attachment is quite strong.

\subsection{Mode of Attachment of Superplasticizers to Cement Grains}

It is a general assumption that the linear superplasticizers e.g. $\beta$-SNFC or SMFC attach themselves to cement grains (or/and cement hydration products) by electrostatic bonding between negative ionic radicals of the polymer chains and positively charged centres of cement grains or cement hydration products. Recently, Fernon et. al has made this assumption more precise [4]. The importance of Fernon et. al's work has been acknowledged in [1]. Fig. (1) shows the bonding model proposed by Fernon et al. [4]. In this model $\beta$-SNFC chains are intercalated within $\mathrm{C}_{4} \mathrm{AH}_{\mathrm{x}}$ crystals. The negative charges of the sulphonate groups of a $\beta$-SNFC chain are electrostatically bonded to the positive holes in the principal layers of $\left[\mathrm{Ca}_{2} \mathrm{Al}(\mathrm{OH})_{6}\right]^{+}$. In view of the importance placed on this model it will be profitable to examine it closely. The proposed model has some unusual features. These are:

a) The $\beta$-SNFC polymers are not linear but have long side chains. The naphthalene molecules at which this branching occurs have peculiar characteristics. Three successive carbon atoms of each of these naphthalene molecules are bonded to three other naphthalene molecules. In Fig. 1 these naphthalene 


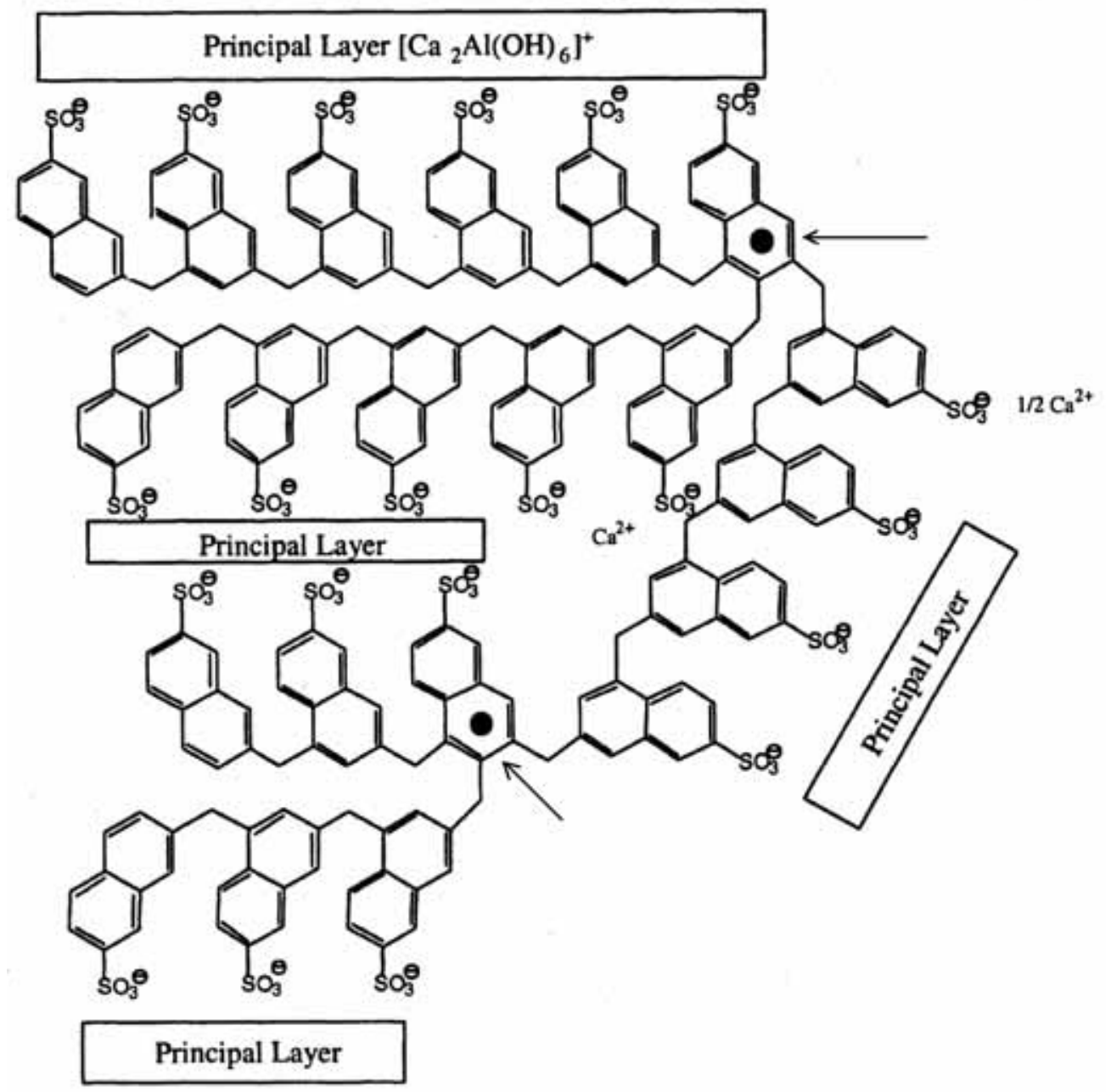

Fig. (1). Postulated bonding of $\beta-S N F C$ with $\mathrm{C}_{4} A H_{x}$.

molecules are marked with black dots and arrows. This type of bonding of three consecutive carbon atoms of one naphthalene molecule to three other naphthalene molecules is rather unusual.

b) Individually these branched $\beta$-SNFC chains form strong electrostatic bonds to a number of principal $\left.\left[\mathrm{Ca}_{2} \mathrm{Al} \mathrm{OH}\right)_{6}\right]^{+}$layers from different $\mathrm{C}_{4} \mathrm{AH}_{\mathrm{x}}$ crystals throughout the paste. Since the bonding between $\beta$ SNFC-principal layers are very strong, the bonded $\beta$-SNFC- $\mathrm{C}_{4} \mathrm{AH}_{\mathrm{x}}$ composites move together during a flow and behave like flocs. The hydrodynamic volumes of these bonded particles are much larger than individual $\mathrm{C}_{4} \mathrm{AH}_{\mathrm{x}}$ crystals. This floc formation is expected to increase resistance to flow of the paste.

c) If $\beta$-SNFC polymers bond other cement materials, both hydrated and anhydrous, in this mode then the paste will be a conglomeration of flocs and not a dispersed phase.

d) One of the corollaries of this mode of bonding is that $\beta$-SNFC polymer will not form bond with negatively charged particles or surfaces.

e) Another corollary is that $\beta$-SNFC will not improve the flow property of a paste made up of particles which were negatively charged to start with. f) Furthermore, in gypsum retarded commercial Portland cement $\mathrm{C}_{4} \mathrm{AH}_{\mathrm{x}}$ is a minor reaction product. As such $\beta$-SNFC- $\mathrm{C}_{4} \mathrm{AH}_{\mathrm{x}}$ bonding is not expected to play an important part in determining the flow characteristics.

In view of the above uncertainties, it will be desirable to ascertain the items (d) and (e). The main objects of this work are to examine the items (d) and (e). In this work a linear polymeric superplasticizer (in the rest of the paper identified as $\beta$-SNFC) and a newer Meta-acrylic acid and Meta-acrylic ester based co-polymeric superplasticizer (in the rest of the paper identified as MA) were included. The last superplasticizer has many side chains but only a few ionic radicals per polymeric molecule.

\section{BASIS OF INVESTIGATION OF THE MODE OF ATTACHMENT BETWEEN SUPERPLASTICIZING POLYMERS AND PARTICLES}

In aqueous solution at about $\mathrm{pH} 3$ silica has no surface charge. Below about $\mathrm{pH} 3$ silica has a positive surface charge and above this $\mathrm{pH}$ surface charge is negative and increases with increasing $\mathrm{pH}$ [5]. Above $\mathrm{pH} 9$ the solubility of silica increases rapidly with increasing $\mathrm{pH}$ [6]. This increasing solubility of silica above $\mathrm{pH} 9$ causes "viscosity" of a silica suspension in water to increase especially if the silica is 


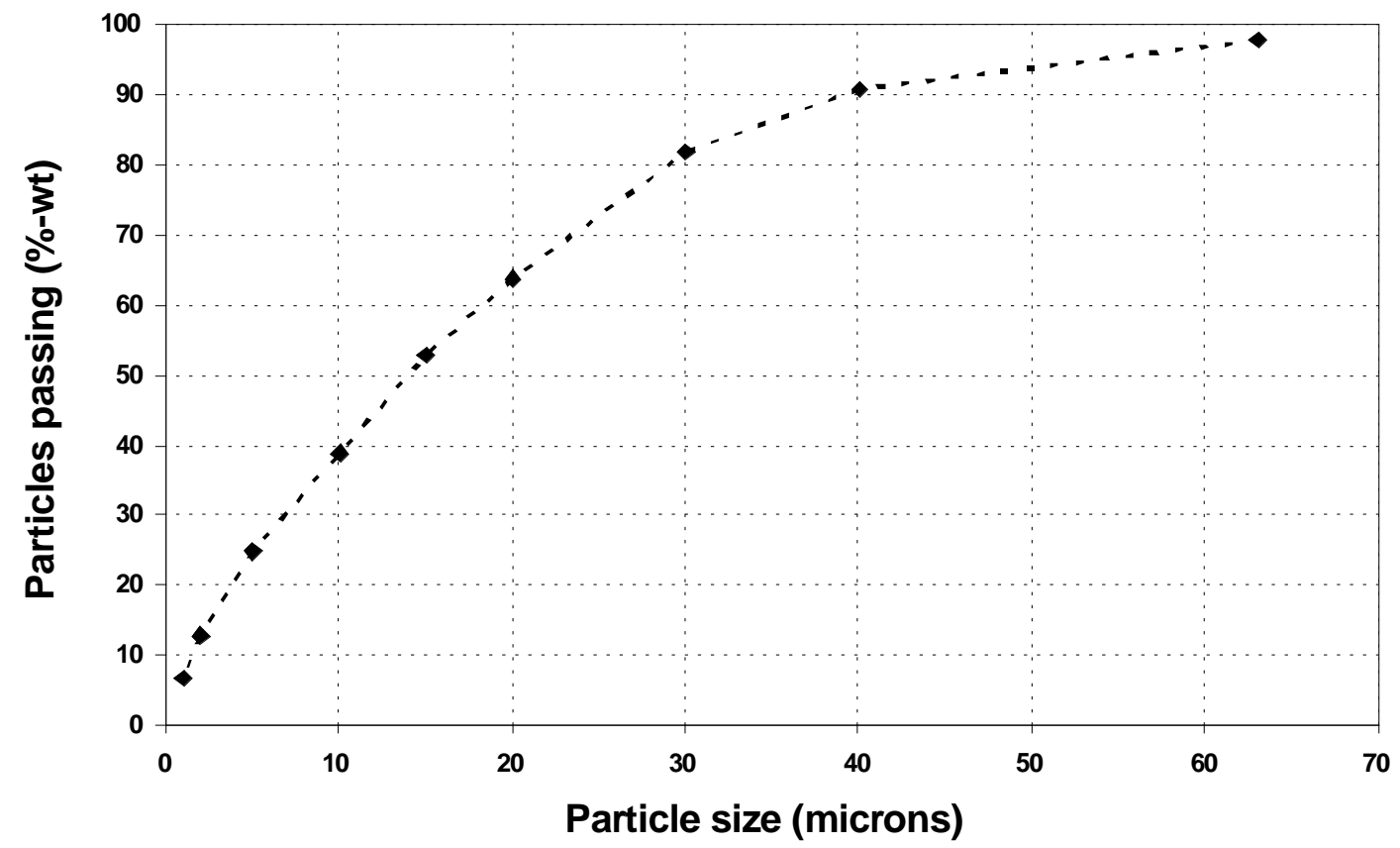

Fig. (2). Size distribution of the quartz power.

finely divided. Advantage has been taken of this charge reversal of silica powder to investigate the mode of attachment of different types of superplasticizers. If the bonding is electrostatic then a superplasticizer molecule with high negative charge, like $\beta$-SNFC, will attach itself with positively charged silica powder below pH 3 but will be repelled from negatively charged silica powder at $\mathrm{pH} 8$ or above. A superplasticizer with a high negative charge, like $\beta$-SNFC, will not function with a silica suspension at $\mathrm{pH} 8$ or above; however, it will function well at $\mathrm{pH}$ below 3 . If however, bonding is other than electrostatic then a superplasticizer like $\beta$ SNFC will function irrespective of the $\mathrm{pH}$ of the suspension. This forms the basis of this investigation.

\section{MATERIALS AND EXPERIMENTAL TECH- NIQUES}

Two types of silica powders, either singly or jointly, were used in this investigation. One type is variously known as silica fume or micro-silica (Grade 983 from Elkem Materials, P.O. Box 8126 Vaagsbygd, N-4675 Kristiansand, Norway). This is a by-product of Ferro-silicon production. This silica consists of nearly spherical, amorphous particles with a specific surface of $22.5 \mathrm{~m}^{2} / \mathrm{g}$. The specific gravity of this micro-silica is $2.2 \mathrm{~g} / \mathrm{ml}$. The second type of silica is a quartz powder SIKRON M300 manufactured by S.C.R Sibelco N.V., Quellinstraat 49, B-2018 Antwerp. The particle size grading of this powder is shown in Fig. 2.

Both the superplasticizers were donated by MAC Spa, Treviso, Italy. $\beta$-SNFC is a commercial product. Normally, acrylic acid based superplasticizers like MA tend to incorporate uncontrolled amount of air in concrete mixes and to avoid this anti-foaming agents are generally incorporated in formulation of these superplasticizers. To avoid complications in the interpretation of the results the superplasticizer MA was specially supplied free of any anti-foaming agent. Before their use both $\beta$ - SNFC and MA were tested on nor- mal 1:3 Portland cement: sand mortars for their dispersing efficiencies and found to be very effective dispersants.

Pastes of silica powders, either singly or in combination, were made with either acid or alkali solutions to obtain workable but not flowing consistency. The flow property of these base pastes were measured at the initially stages qualitatively. However, at later stages the consistency was measured with a mini slump cone according to the method described by Kantro [7]. After the evaluation of the flow property of a base paste a chosen superplasticizer was added to the paste, mixed and then the flow property was remeasured. The difference between the above two flow properties is a measure of the effectiveness of the chosen superplasticizer in either acid or alkali solution. The details of individual mix composition and resulting flow property are provided in Tables 1-4 in the following section.

\section{RESULTS AND DISCUSSIONS}

\subsection{Qualitative Evaluation of Interaction Between Mi- cro-Silica and $\beta-S N F C$ in Alkaline Solutions}

The results in Table 1 show that the stiffness of silica fume + alkali solution mixtures increases with increasing $\mathrm{NaOH}$ concentration and requires higher addition of $\beta$-SNFC to make the mixes fluid or workable. A paste with $0.5 \mathrm{~N}$ $\mathrm{NaOH}$ solution is unworkable and could not be made workable by adding reasonable amount of $\beta$-SNFC. The increase of the stiffness with $\mathrm{NaOH}$ concentration of the base paste is related to the formation of silica gel with increasing $\mathrm{NaOH}$ concentration. Higher consumption of $\beta$-SNFC with increasing $\mathrm{NaOH}$ concentration could be partly due to its adsorption by silica gel. However, it is of interest to note that even a micro-silica paste made with $0.1 \mathrm{~N} \mathrm{NaOH}$ solution could be made workable by adding sufficient amount of $\beta$-SNFC. The results also show that the efficiency of $\beta$-SNFC is not affected by negatively charged micro-silica grains and/ or negatively charged silica gel. 
Table 1. Effect of Addition of $\beta$-SNFC to Alkaline Micro-Silica Pastes

\begin{tabular}{|c|c|c|c|c|c|c|}
\hline $\begin{array}{l}\text { Micro- } \\
\text { Silica (g) }\end{array}$ & $\begin{array}{l}\text { Conc. of } \mathrm{NaOH} \\
\text { in Soln. (N) }\end{array}$ & $\begin{array}{c}\mathrm{NaOH} \\
\text { Added (g) }\end{array}$ & $\begin{array}{c}\text { Flow Characteristics } \\
\text { of Base Paste }\end{array}$ & $\begin{array}{c}\beta \text {-SNFC, } \\
\text { Drops }\end{array}$ & $\begin{array}{c}\text { Flow } \\
\text { Characteristics After } \\
\text { B-SNFC Addition }\end{array}$ & Remarks \\
\hline 30 & 0.05 & 12 & Stiff paste & 3 & Very fluid & Fluidity lasted for at least $3 \mathrm{~h}$ \\
\hline 30 & 0.1 & 12 & Very stiff paste & 6 & Workable paste & Workability lasted for $2 \mathrm{~h}$ \\
\hline
\end{tabular}

Table 2. Effect of Addition of $\beta$-SNFC and MA to Acidic and Alkaline Micro-Silica Pastes

\begin{tabular}{|c|c|c|c|c|c|}
\hline Microsilica (g) & Solution (Strength, type) & Solution (g) & $\begin{array}{c}\text { Flow of the Base } \\
\text { Paste (mm) }\end{array}$ & Superplasticizer (ml) & $\begin{array}{c}\text { Flow of Modified Paste } \\
\text { (mm) }\end{array}$ \\
\hline \hline 300 & $0.05 \mathrm{~N}, \mathrm{HCl}$ & 150 & 89.5 & $\beta-S N F C, 2$ & 128.5 \\
\hline 300 & $0.05 \mathrm{~N}, \mathrm{NaOH}$ & 150 & $40^{* *}$ & $\beta-S N F C, 1$ & 113.5 \\
\hline 300 & $0.05, \mathrm{~N} \mathrm{HCl}$ & 150 & 85 & MA, 2 & No flow* \\
\hline 300 & $0.05 \mathrm{~N}, \mathrm{NaOH}$ & 150 & $40^{* *}$ & MA, 2 & No flow* \\
\hline
\end{tabular}

* No flow indicates that the paste did not increase in diameter.

** The diameter of the paste did not increase after the removal of the mini-slump cone.

Table 3. Effect of Addition of $\beta$-SNFC and MA to Alkaline Micro-Silica-Quartz Powder Pastes

\begin{tabular}{|c|c|c|c|c|}
\hline $\begin{array}{c}\text { Quartz Powder/Micro- } \\
\text { Silica (g/g) }\end{array}$ & $\begin{array}{c}0.025 \mathrm{~N} \text { NaOH Soln } \\
(\mathrm{g})\end{array}$ & $\begin{array}{c}\text { Flow of the Base Paste } \\
(\mathrm{mm})\end{array}$ & $\begin{array}{c}\text { Superplasticizer, (Type, ml } \\
\text { Added) }\end{array}$ & $\begin{array}{l}\text { Flow After the Addition of } \\
\text { the Superplasticizer (mm) }\end{array}$ \\
\hline $400 / 100$ & 113.5 & 85 & $\beta$-SNFC, 2 & 148 \\
\hline $400 / 100$ & 113.5 & 86 & MA, 2 & 90 \\
\hline
\end{tabular}

\subsection{Effects of $\beta$-SNFC or MA on the Fluidity of Acidic and Alkaline Pastes of Micro-Silica}

Table 2 shows that superplasiticising efficiency of $\beta$ SNFC is independent of acidity and alkalinity of the paste i.e. of the positive or negative surface charge of micro-silica grains. $\beta$-SNFC works equally well both in acidic and alkaline conditions. It has to be noted that $\mathrm{HCl}$ has a dispersing effect on micro-silica paste. Elkem commercially sells a low viscosity acid stabilized $50 \%$ microsilica suspension. Addition of MA to acid fluidized micro-silica suspension causes the whole mass to gel. We have previously observed similar gel formation with acid stabilized $50 \%$ micro-silica suspension from Elkem. MA is not an effective dispersant of microsilica either in acidic or alkaline environment. An explanation of this apparent contradiction with the results of $1: 3$ Portland:sand mortar will be presented in a later section.

\subsection{Effects of $\beta$-SNFC or MA on the Fluidity of Alkaline Pastes of Micro-Silica- Quartz Powder Mixtures}

This series of experiments was carried out to simulate cement mortar condition where solution is alkaline and solid powder is a mixture of coarse and fine particles. Note the high content of microsilica in these mixes. Table 3 shows that in these high micro-silica content mixes $\beta$-SNFC is a more effective superplasticizer than MA. However, unlike the case of alkaline paste with MA in Table $\mathbf{2}$, Table $\mathbf{3}$ shows a small but definite increase in flow i.e. from $86 \mathrm{~mm}$ to 90 $\mathrm{mm}$. The consistency of this paste is also different; it has a creamy consistency. To clarify the situation low fine mixes were studied. Table 4 shows the mix compositions and the results of flow measurements. In these low fine mixes, acidic solution always produces a flowing base paste. Addition of 3 $\mathrm{ml} \beta$-SNFC to the acidic paste increases the flow value from 71.4 to $130 \mathrm{~mm}$. Addition of $2 \mathrm{ml} \mathrm{MA}$ to the acidic base paste decreases the flow value from 85 to "No flow", i.e. MA causes flock formation in an acid dispersed paste. In alkaline environment the base paste does not flow which could be due to the formation of silica gel caused by the high alkali solution/micro-silica ratio of the mix and associated high silica gel formation. An addition of $3 \mathrm{ml} \beta$-SNFC to an alkaline paste has no effect on its flow value. This could be due to the adsorption of $\beta$-SNFC on silica gel. An addition of $2.5 \mathrm{ml}$ MA on the other hand increases the flow so much that the coarser quartz powder segregates out and the dispersed suspension of micro-silica continues to flow beyond 180 $\mathrm{mm}$.

\section{SOME INTERMEDIATE INFERENCES}

From the above results the following intermediate inferences could be drawn: 
Table 4.

\begin{tabular}{|c|c|c|c|c|}
\hline $\begin{array}{c}\text { Quartz Powder/ Micro-Silica, } \\
\text { g/g }\end{array}$ & $\begin{array}{c}\text { Solution } \\
\mathbf{0 . 0 5 N}, \mathbf{g},\end{array}$ & $\begin{array}{c}\text { Flow of the Base Paste, } \\
\mathbf{m m}\end{array}$ & $\begin{array}{c}\text { Superplasticizer, Volume } \\
\text { Added, ml }\end{array}$ & $\begin{array}{c}\text { Flow After the Addition } \\
\text { of the Agent, } \mathbf{m m}\end{array}$ \\
\hline \hline $500 / 15$ & $\mathrm{HCl}, 132.8$ & 71.4 & $\beta-\mathrm{SNFC}, 2$ & 130 \\
\hline $500 / 15$ & $\mathrm{NaOH}, 160$ & No flow & $\beta-\mathrm{SNFC}, 3$ & No flow \\
\hline $500 / 15$ & $\mathrm{HCl}, 132.8$ & 85 & $\mathrm{MA}, 2(+2)$ & No flow* \\
\hline $500 / 15$ & $\mathrm{NaOH}, 160$ & No flow & MA, 2,5 & $180^{* *}$ \\
\hline
\end{tabular}

* Addition of extra $2 \mathrm{ml}$ of MA did not affect the flow.

** The paste segregated i.e. quartz powder settled at the bottom and the dispersed micro-silica suspension continued to flow beyond 180 mm.

i. In acidic solutions micro-silica, mixtures of microsilica and quartz powder are well dispersed and have high fluidity.

ii. In alkaline solutions micro-silica forms silica gel. The higher the alkali hydroxide concentration the higher is the silica gel formation and stiffer is the mixture.

iii. The superplasticizing effect of $\beta$-SNFC on microsilica containing pastes is independent of the acidity or alkalinity of the paste. However, there is critical alkalinity above which silica gel formation is so high that the paste could not be dispersed with reasonable quantity of $\beta$-SNFC.

iv. Addition of MA to pure micro-silica paste with acidic or alkaline solutions causes floc formation. In acidic paste the addition of MA actually counteract the dispersing effect of acidic solution.

v. Addition of MA to acidic pastes of the micro-silicaquartz powder mixture causes floc formation.

vi. Addition of MA to alkaline pastes of the microsilica-quartz powder mixture increases flow characteristics of the paste. This is particularly so with low micro-silica pastes.

\section{MODES OF ATTACHMENT OF SUPERPLASTI- CIZER POLYMERS TO SOLID PARTICLES}

\subsection{Attachment of $\beta$-SNFC Molecules to Solid Particles}

The results of the present investigation show that the superplasticizing effect of $\beta$-SNFC polymer is not affected by the acidic or alkaline nature of micro-silica containing pastes. This also indicates that the attachment of $\beta$-SNFC to micro-silica particles does not depend on the positive or negative electrical charges on the particles. Another mode of attachment is required to explain the attachment of $\beta$-SNFC to micro-silica particles. HLB (hydrophilic-lipophilic balance) scheme suggests another such mode of attachment [2, 8].

In $\beta$-SNFC polymer, the sulphonic acid radicals are hydrophilic and poly-naphthaleneformaldehyde condensate chains are hydrophobic (lipophilic). When $\beta$-SNFC molecules are added to an aqueous suspension of solid particles, the long-chained hydrophobic parts are deposited on to the solid particles with the short sulphonic radicals in solution. Depending upon the nature, shape and size of the solid parti- cles and chain lengths of the hydrophobic part, the hydrophobic backbones could assume linear or train and loop configurations. A schematic representation of this mode of attachment is shown in Fig. 3. In Fig. 3 the sulphonic acidic radicals are shown as arrows pointing to the aqueous phase. This mode of attachment is indifferent to the electrical charges on the solid particles. However, the sulphonic acid radicals immediately impart multiple negative charges on the coated solid particles. In Portland cement paste, the addition of $\beta$-SNFC immediately increases zeta potential from \pm 8 to $35 \mathrm{mV}$ [9]. There is a side-effect of this mode of attachment. The hydrophobic poly-naphthalene-formaldehyde condensate chains will cover larger areas of the particles than sulphonate radicals. In the case of Portland cement paste, this coverage by hydrophobic backbones protects the covered areas from easy access to water and thereby slows the rate of cement hydration, i.e. $\beta$-SNFC acts as a retarding agent especially at high dosages.

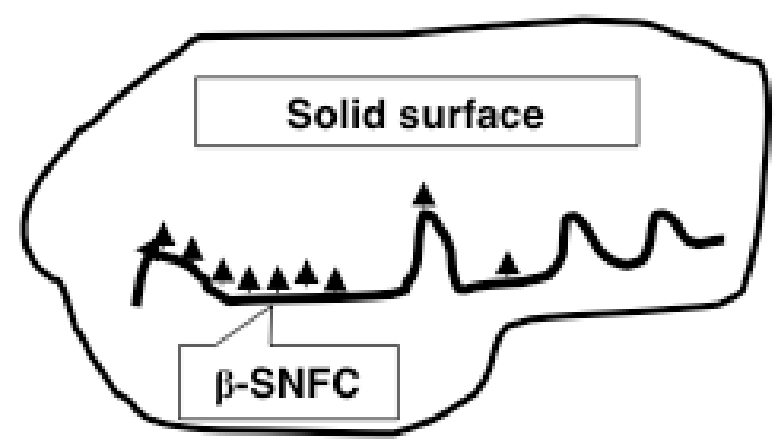

Fig. (3). Suggested attachment of $\beta$-SNFC to solid particles. Some of the sulphonate groups have been depicted as arrows with the arrowheads pointing to water.

\subsection{Attachment of MA on to Solid Particles}

This polymeric molecule contains only few ionic radicals so that ionic attachment can not play a dominant role. However, the mode of attachment of $\beta$-SNFC to solid particles, with some modification, could be applied to MA as well. A schematic representation of this modified mode of attachment is shown in Fig. 4. Fig. 4 shows that MA has more than one hydrophobic part in each polymeric molecule. MA molecules could have either closed or extended configuration in an aqueous solution depending up on the $\mathrm{pH}$. Due to the presence of multiple hydrophobic parts, each molecule of 


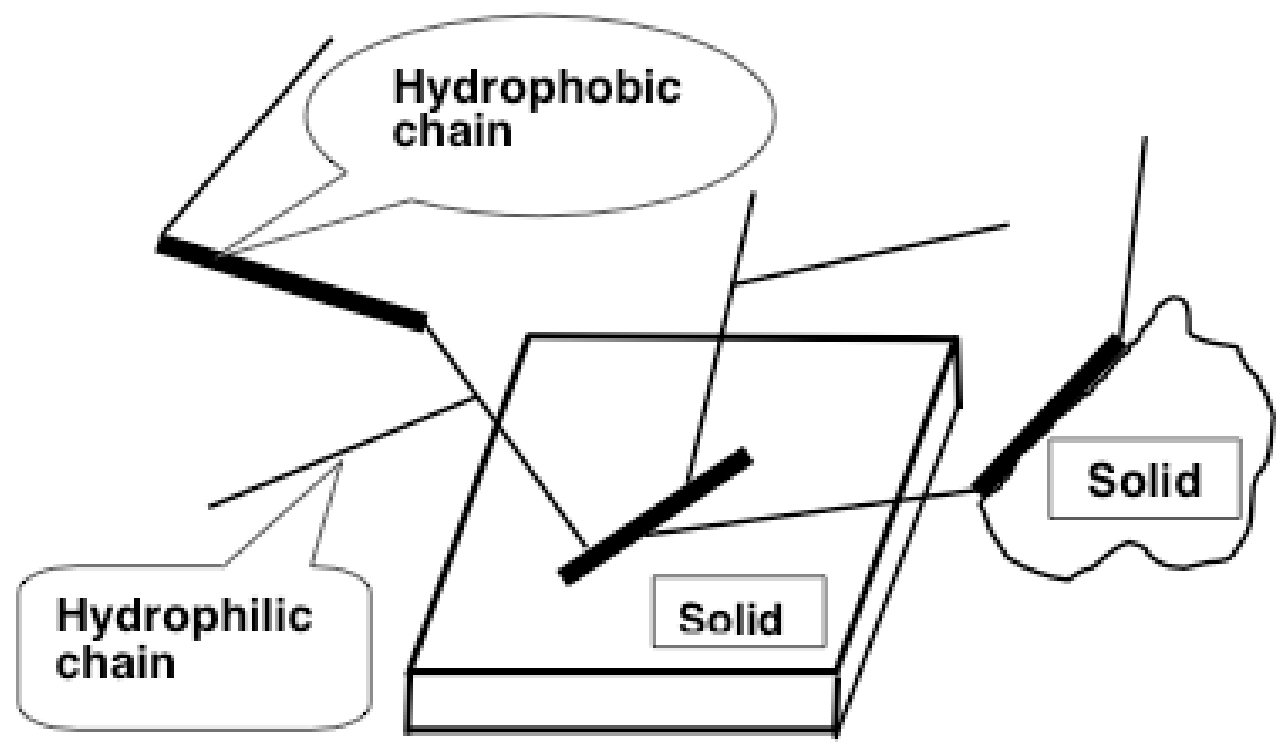

Fig. (4). Suggested attachment of MA to multiple solid particles.

MA could be attached, under suitable conditions, to more than one solid particle. Fig. 4 depicts two solid particles attached to a single MA molecule. The possibility of formation of attachment to multiple solid particles increases with increasing number density of solid particles per volume of the paste. The possibility of multi-particle attachment also increases if MA has an extended configuration.

With the above modifications, it is possible to explain the observed effects of MA addition to micro-silica containing pastes (Tables 2, 3 and 4 ). The number density of microsilica particles in pastes of Table $\mathbf{2}$ is so high that each MA polymer molecule could attach to a number of microsilica particles. This happens irrespective of the configuration of MA in acidic or alkaline solution. This multiple attachment causes formation of large flocs and the flow property of the paste is drastically decreased. In the paste of Table $\mathbf{3}$ the number density of micro-silica is lower than that in Table $\mathbf{2}$. Addition of MA to the alkaline version of this paste results in a small improvement in its flow characteristics. Table $\mathbf{4}$ shows the effect of changed configuration of MA in acidic and alkaline environments. An acidic environment favours an extended configuration of MA. This extended configuration of MA allows for extensive multiple MA-micro-silica attachment even in this low micro-silica paste. This results in extensive floc formation and reduced flow. In alkaline environment, however, MA has a closed configuration thereby reducing the possibility of multiple MA-micro-silica attachment. Under this condition MA could show its dispersing ability fully. This results in the segregation of coarse quartz particles and high flow of the micro-silica suspension.

In the case of Portland cement paste, the above mode of attachment has a side effect. Hydration of Portland cement produces a large number of cement hydration products in the vicinity of the hydrating cement grains. This high number density of hydration products could facilitate multiple MAparticle attachments and local formation of flocs. These flocs being of open structure allow for easy access of water to the hydrating cement grains. The net result is a nearly uninhibi- ted rate of cement hydration. This is in contrast to reduced rate of cement hydration in the case of $\beta$-SNFC.

\section{CONCLUSIONS}

The results of this investigation show that the attachment of $\beta$-SNFC to solid particles does not dependent on the electrical charges on the solid particles. $\beta$-SNFC attaches equally well on negative and positively charged silica particles. The $\beta$-SNFC molecule is composed of two components. Polynaphthalene-formaldehyde condensate part is hydrophobic and the sulphonic part is hydrophilic. When $\beta$-SNFC is added to an aqueous suspension of particles, the hydrophobic part is deposited on the particle surface with the sulphonic acid radicals in the aqueous phase. The resulting coated particles have net negative charge and negative zeta potential. The coated particles are dispersed. With some modifications, the above mode of attachment does also apply to superplasticizers based on Meta-acrylic acid and Meta-acrylic ester based co-polymer.

\section{REFERENCES}

[1] R.J. Flatt, "Polymeric Dispersants in Concrete", in Polymers in Particulate Systems, Properties and Applications, eds. Hackley, Somasundaran, and Lewis, Marcel Dekker, Inc., 2001. pp. 247-294.

[2] D.H. Napper, Polymeric Stabilization of Colloidal Dispersions, London: Academic Press, 1983. pp. 28. (This monograph is an extensive discussion on this topic).

[3] J.D. Connelly, W.G. Hime, B. Erlin, "Analysis for admixtures in hardened concrete", Concrete International, Concrete Society, London, 1980.

[4] V. Fernon, A. Vichot, N. Le Goanvic, et al., "Interaction between Portland cement hydrates and polynaphthalene sulfonates", in Proc. 5th Canmet/ACI Intern. Conf. Superplasticizers and Other Chemical Admixtures in Concrete, ed. V. Malhotra, Rome, 1997, pp. 225248.

[5] R.K. Iler, The Chemistry of Silica, New York: John Wiley \& Sons Inc, 1979. pp. 186 .

[6] R.K. Iler, The Chemistry of Silica, New York: John Wiley \& Sons Inc, 1979. pp. 367.

[7] D.L. Kantro, "Influence of Water-Reducing Admixtures on Properties of Cement Paste - A Miniature Slump Test", Cement, Concrete, and Aggregates, No. 2, 1980, pp. 95-102. 
P. Krsko, M. Libera, "Biointeractive hydrogels", Materialstoday, No. 8, 2005, pp. 36-44.

[9] E.M. Gartner, H. Koyata, P. Scheiner, "Influence of. Aqueous Phase Composition on the Zeta Potential of Cement in the presence of Water-Reducing Admixture", in "Cement Technology", eds. Gartner and Uchikawa, Ceramic Transactions, Vol. 40, Am. Ceramic Soc., 1994. pp. 131-140.

(c) Pade and Chatterji; Licensee Bentham Open.

This is an open access article distributed under the terms of the Creative Commons Attribution License (http://creativecommons.org/license/by/2.5/), which permits unrestrictive use, distribution, and reproduction in any medium, provided the original work is properly cited. 